\title{
Genetic Behavior of Controlling Area Under Disease Progress Curve for Stripe Rust (Puccinia striiformis f. sp. tritici) in Two Wheat (Triticum aestivum) Crosses
}

\author{
Muhammad Irfaq, Mir Ajab, Gul Sanat Shah Khattak, Tila Mohammad, and Syed Jawad Ahmad Shah
}

First, third, fourth, and fifth authors: Plant Breeding and Genetics Division, Nuclear Institute for Food and Agriculture (NIFA), Peshawar, N.W.F.P., Pakistan; and second author: Department of Plant Sciences, Quaid-i-Azam University, Islamabad, Pakistan. Accepted for publication 25 April 2009.

\section{ABSTRACT}

Irfaq, M., Ajab, M., Khattak, G. S. S., Mohammad, T., and Shah, S. J. A. 2009. Genetic behavior of controlling area under disease progress curve for stripe rust (Puccinia striiformis f. sp. tritici) in two wheat (Triticum aestivum) crosses. Phytopathology 99:1265-1272.

Genetic effects on controlling resistance to stripe rust (Puccinia striiformis f. sp. tritici Eriksson)were determined in two wheat crosses, Bakhtawar-92 (B-92) $\times$ Frontana and Inqilab-91 $\times$ Fakhre Sarhad using area under the disease progress curve (AUDPC) as a measure of stripe rust resistance. The resistant and susceptible parents involved in developing genetic populations were identified by initial assessment of 45 wheat accessions for stripe rust reaction. Mixed inheritance model was applied to the data analysis of six basic populations $\left(\mathrm{P}_{1}, \mathrm{~F}_{1}, \mathrm{P}_{2}, \mathrm{~B}_{1}, \mathrm{~B}_{2}\right.$, and $\mathrm{F}_{2}$ ) in the crosses. The results indicated that AUDPC in cross 1 was controlled by two major genes with additive-dominance epistatic effect plus polygenes with additive-dominance-epistatic effects (model E) whereas, in the case of cross 2 , it was under the control of two major genes with additive-dominance epistatic effect plus additive-dominant polygenes (model E-1). Additive effect was predominant over all other types of genetic effects, suggesting that the delay in selection for resistance until maximum favorable genes are accumulated in the individuals is desired. The tendency of backcrosses toward their respective pollen donor parents indicated the control of resistance through nuclear genes rather than the cytoplasmic factors. Occurrence of resistant as well as susceptible transgressive segregates (though very few in $F_{2}$ for each cross) indicated the presence of favorable as well as some adverse genes for resistance to stripe rust in the parents. The major gene heritability was higher than that of the polygene in $\mathrm{B}_{1}, \mathrm{~B}_{2}$, and $\mathrm{F}_{2}$ for the crosses. The major gene as well as the polygene heritability was 48.99 to $87.12 \%$ and 2.26 to $36.80 \%$ for the two crosses, respectively. The highest phenotypic variations in AUDPC (2,504.10 to 5,833.14) for segregating progenies $\left(B_{1}, B_{2}\right.$, and $\left.F_{2}\right)$ represent that the character was highly influenced by the environment. The experimental results of the two crosses indicate that resistance to stripe rust is under control of two major genes in association with several polygene rather than cytoplasmic inheritance.
Stripe (yellow) rust, caused by a fungus Puccinia striiformis f. sp. tritici Eriksson (an obligate biotrophic organism), is a major disease of wheat worldwide, especially in moist and cool environments, including Asia, the Middle East, Europe, North America, South America, and Africa (16,27). The disease appeared in epidemic form in many wheat-growing areas of Pakistan during 2005 because of the indirect tsunami effect on the country when the environmental conditions were highly conducive due to excessive rain and associated humid conditions from February until April. Grain yield losses of 10 to $70 \%$ have been reported depending upon the cultivar grown and conducive environmental conditions during ear emergence $(13,27)$. Cultivation of genetically resistant cultivars is the most effective, environmentally safe, and economical measure to control the disease. Racespecific or vertical resistance is no longer effective because of the evolution and population diversity of new virulent pathotypes (11). Durable resistance controlled by the combined effect of both major and minor genes is desired to control the disease for a longer time in an environment conducive for the disease development. This requires the availability of well-known resistant genetic resources, a better understanding of the host-pathogen interaction, and effective techniques to utilize the desired genes. Adult plant resistance is most often desired by wheat breeders in order to reduce yield losses caused by the disease at the stage of

Corresponding author: M. Irfaq; E-mail address: irfaqk@ hotmail.com

doi:10.1094/PHYTO-99-11-1265

(c) 2009 The American Phytopathological Society ear emergence (15). Identification of genetically variable lines with respect to stripe rust resistance is of great help to select the parents for cross combination so as to pyramid genes from different resistant resources into a single genotype with durable resistance. The aims of the present study were to (i) identify genotypes with diverse genetic nature, especially with high and low level of resistance to stripe rust; (ii) attempt cross combinations between highly resistant and highly susceptible genotypes and creation of six basic populations for genetic studies; and (iii) study the genetic basis of stripe rust resistance in the selected crosses by using area under the disease progress curve (AUDPC) as a measure of resistance to the disease.

\section{MATERIALS AND METHODS}

Creation of artificial epiphytotic conditions. Seed of 45 bread wheat genotypes differing in their genetic make up and origin were collected from different sources (Table 1). The accessions were planted as a stripe rust screening nursery in two replications in plots of $1.2 \mathrm{~m}^{2}$, consisting of two rows $(2 \mathrm{~m} \mathrm{long})$ per entry with 20 seeds per row, in a randomized complete block design (RCBD) at an experimental field of the Nuclear Institute for Food and Agriculture (NIFA), Peshawar, Pakistan, during November 2003 to April 2004. The site is situated at latitude $34^{\circ} 01^{\prime} \mathrm{N}$ and longitude $71^{\circ} 40^{\prime} \mathrm{E}$, at an altitude of $347 \mathrm{~m}$ above mean sea level.

Each entry of the nursery was bordered with susceptible stripe rust spreader 'Morocco'. As referred (30), artificial epiphytotic 
conditions were created in the field by inoculating the nursery material at tillering stage in late afternoon with a uniform spray of spore suspension containing a mixture of urediospores of different stripe rust ( $P$. striiformis) pathotypes prevalent in Pakistan through a turbo air sprayer at the end of February 2004. The inoculum was obtained from the Crop Diseases Research Program, Institute of Plant and Environmental Protection, National Agriculture Research Centre, Islamabad, Pakistan. The inoculum used in the present study has the virulence against $Y r 1, Y r 2, Y r 6$, $Y r 7, Y r 9, Y r 17, Y r A$, and $Y r 27$ and avirulance for $Y r 3, Y r 5, Y r 10$, Yr15, Yrsp, and $Y r C v$ (24). Spore inoculum was produced by dissolving urediospores at a rate of $1 \mathrm{~g} /$ litter with approximate concentration of $10,000 / \mathrm{ml}$ in the suspension as determined by hemacytometer. Subsequently, Tween 20, as an emulsifying agent, was added. The higher concentration of the spores was used in order to create maximum artificial disease pressure under field conditions. The nursery material was then kept covered for $48 \mathrm{~h}$ with plastic sheets to retain moisture for making conditions conducive to spore germination. On the third day of inoculation, plastic sheets were removed. In order to make conditions conducive for spore multiplication and disease development, spraying with plain water in the late afternoon on each second day was conducted on the nursery material for a fortnight until disease symptoms appeared in the field.

Recording disease severity and calculation of AUDPC for germplasm. After successful disease development, as suggested $(12,13,19)$, data for rust severity (percentage of leaf area with symptoms) were recorded on the top three leaves of five randomly selected plants from each of 45 accession on rating scale of 0 to 9 points (18) with little modifications from that of Doling (7). Rust severity was determined by visual observation according to the modified Cobb scale (23). For recording correct readings of

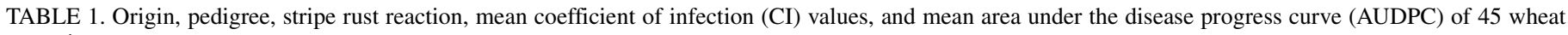
accessions $^{\mathrm{a}}$

\begin{tabular}{|c|c|c|c|c|c|c|c|}
\hline \multirow[b]{2}{*}{ Genotype } & \multirow[b]{2}{*}{ Origin } & \multirow[b]{2}{*}{ Pedigree } & \multicolumn{2}{|c|}{ Reaction to stripe rust ${ }^{b}$} & \multicolumn{2}{|c|}{$\mathrm{CI}$} & \multirow[b]{2}{*}{ AUDPC } \\
\hline & & & $1 \mathrm{st}$ & 2nd & $1 \mathrm{st}$ & 2nd & \\
\hline Frontana & Brazil & Fronteria/Mentana & $\operatorname{Tr}$ & 20RMR & 1.20 & 4.65 & 35.10 \\
\hline Bakhtawar-92 & CIMMYTc & KAUZ 'S' & 20MRMS & 20MSS & 7.30 & 16.60 & 143.40 \\
\hline Saleem-2K & CIMMYT & CHAM-6//KITE/PGO & 10MSS & 10MSS & 6.90 & 10.30 & 103.20 \\
\hline Tatara & CIMMYT & JUP/ALD "S"//RLT 'S'/3VEE 'S') & $\mathrm{O}$ & 10RMR & 1.41 & 6.20 & 45.67 \\
\hline Fakhre Sarhad & CIMMYT & PFAU 'S'/SERI/BOW 'S' & 5MSS & 20RMR & 2.65 & 7.40 & 60.29 \\
\hline CT-02009 & CIMMYT & PUNJAB-96-0PAK & $\mathrm{O}$ & 20MR & 4.57 & 10.94 & 93.06 \\
\hline CT-02019 & CIMMYT & KAUZ//STAR/LUCO-M & 20MRMS & $5 \mathrm{MS}$ & 4.01 & 12.00 & 99.91 \\
\hline CT-02081 & CIMMYT & VEE/TRAP\#1//ANGRA/3/PASTOR & 10MSS & 20MRMS & 4.01 & 12.00 & 96.06 \\
\hline CT-02192 & CIMMYT & IRENA//CMH76.176/2*GEN/3/SNB/4/BORL95 & TMSS & 10RMR & 6.52 & 22.70 & 175.31 \\
\hline CT-02266 & CIMMYT & SW89.5181/KAUZ & $\operatorname{Tr}$ & 10MRMS & 2.71 & 8.80 & 69.05 \\
\hline CT-02267 & CIMMYT & SW89.5181/KAUZ & $10 \mathrm{~S}$ & $5 \mathrm{~S}$ & 2.91 & 11.20 & 84.68 \\
\hline CT-02204 & CIMMYT & KAUZ/PASTOR & $\mathrm{R}$ & 10MRMS & 5.37 & 8.40 & 82.61 \\
\hline CT-02306 & CIMMYT & CMH80A.542/CNO79 & 5MRMS & $10 \mathrm{~S}$ & 6.12 & 17.50 & 141.72 \\
\hline CT-02248 & CIMMYT & ALTAR84/AE.SQUARROSA(219)//SERI & $5 \mathrm{MS}$ & 20MS & 5.65 & 11.13 & 100.62 \\
\hline CT-02390 & CIMMYT & FRET2 & $5 \mathrm{~S}$ & $5 \mathrm{MS}$ & 4.00 & 8.87 & 77.22 \\
\hline CT-01183 & CIMMYT & SITTA/*SKUZ & 5RMR & $10 \mathrm{~S}$ & 2.45 & 12.90 & 93.66 \\
\hline CT-01084 & CIMMYT & ATTILA/3*BCN & $20 \mathrm{~S}$ & $50 \mathrm{~S}$ & 6.72 & 14.22 & 122.40 \\
\hline Inqilab-91 & CIMMYT & WL 711/CROW 'S' & $20 \mathrm{MR}$ & 20MRMS & 12.60 & 28.20 & 244.80 \\
\hline Karawan & CIMMYT & $\mathrm{C} 182.2 / \mathrm{C} 166.3 / 3 / \mathrm{CNO} / 7 \mathrm{C} 2 * / / \mathrm{CC} / / \mathrm{TOB} / \mathrm{SWM} 6828$ & $\mathrm{O}$ & 20R & 4.45 & 7.30 & 70.50 \\
\hline CT-99022 & CIMMYT & URES/JUN//KAUZ & 20MSS & 40MSS & 3.55 & 9.20 & 76.50 \\
\hline Metal Tail & India & $\mathrm{ORE} \mathrm{F}_{1}$ 158/FDL//KAL/BB/3/NAC & $30 \mathrm{MR}$ & 30MRMS & 9.24 & 14.85 & 144.53 \\
\hline V-84051 & India & TAN'S'/3/TI/TOB//ALD & 20RMR & 20MRMS & 12.40 & 20.00 & 194.40 \\
\hline Soleman-96 & CIMMYT & Pedigree not available & $\operatorname{Tr}$ & 10MSS & 4.90 & 25.20 & 180.60 \\
\hline CB-61 & CIMMYT & MILAN/HD.832 PK.3484-3A-3A-500A & $10 \mathrm{MR}$ & 20MSS & 4.70 & 15.60 & 121.80 \\
\hline CB-82 & CIMMYT & SATLUJ 86CMT/YR//MON 'S' & 5RMR & 30MRMS & 4.30 & 15.80 & 120.60 \\
\hline CB-148 & CIMMYT & WEAVER/TSC//WEAVER/3/WEAVER & 10MRMS & 20MRMS & 6.25 & 14.40 & 35.10 \\
\hline CB-179 & CIMMYT & GAMDOW-6/CM79515-044Y... & 10MRMS & 20MRMS & 7.50 & 18.30 & 143.40 \\
\hline CB-185 & CIMMYT & PASTOR-2/CM85295-0101TOPY-- & 10MRMS & 10MSS & 3.34 & 12.40 & 103.20 \\
\hline CB-195 & CIMMYT & MAYA74 'S'/MON'S' & $10 \mathrm{R}$ & 10MSS & 7.80 & 13.80 & 45.67 \\
\hline CB-196 & CIMMYT & MAYA74 'S'/MON CM 29480-20Y0Y & $20 \mathrm{~S}$ & 30MSS & 9.60 & 20.60 & 60.29 \\
\hline CB-197 & CIMMYT & PF70402/ALD'S'//PAT72/160//ALD'S'/3/PEW 'S' & 20RMR & 40MSS & 12.80 & 26.80 & 93.06 \\
\hline CB-289 & CIMMYT & BOW'S'*2/PRL'S' & 20MR & 30MRMS & 9.60 & 32.20 & 99.91 \\
\hline Uqab-2K & CIMMYT & CROW'S'/NAC//BOW'S'PB 22138 & 20MSS & 30MRMS & 9.40 & 16.80 & 96.06 \\
\hline CB-325 & CIMMYT & TAN'S'/3/TI/TOB//ALD = V-84051 & 10MRMS & 40MRMS & 13.45 & 16.20 & 175.31 \\
\hline DRRM & India & PB-96/V-87094//MH-97 & 10MSS & 10MRMS & 7.30 & 17.60 & 69.05 \\
\hline CM-03-04 & India & PASTOR/3/VEE\#5DOVE/BUC & 30MRMS & 30MR & 8.67 & 11.50 & 84.68 \\
\hline E-41 & India & SH-88/PAK-81//MH-97 & $10 \mathrm{MR}$ & 30MRMS & 12.30 & 15.20 & 82.61 \\
\hline V-2156 & India & Weaver/SH-88 & 20RMR & 50RMR & 8.52 & 11.30 & 141.72 \\
\hline V-03007 & India & $\mathrm{Pb}-96 / \mathrm{V}-87094 / / \mathrm{MH}-97$ & $\mathrm{O}$ & $30 \mathrm{MR}$ & 3.59 & 8.00 & 100.62 \\
\hline AS-2002 & India & Pedigree not available & $30 \mathrm{MR}$ & 20MRMS & 6.20 & 10.40 & 77.22 \\
\hline CB-145 & India & CHOIX/STAR/3/HE1/3*CNO79//2*SERI & $\mathrm{O}$ & $5 \mathrm{~S}$ & 2.65 & 11.60 & 93.66 \\
\hline Mango & CIMMYT & RSK/AZ//PVN/CM 4170-9 & 10MRMS & 20MRMS & 7.75 & 22.70 & 122.40 \\
\hline BANA-4 & India & Pedigree not available & 20MRMS & $60 \mathrm{MS}$ & 8.40 & 13.35 & 244.80 \\
\hline CB-171 & India & ABTIN-1ICW92-0717 & 20MRMS & 30MSS & 5.21 & 13.30 & 70.50 \\
\hline E-29 & India & SH-88/V-90A 204//MH-97 & 10MSS & 20MSS & 15.90 & 16.75 & 76.50 \\
\hline
\end{tabular}

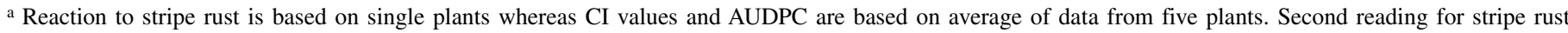
reaction was recorded 12 days after the first reading.

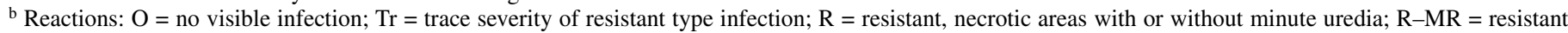
to moderately resistant; $\mathrm{MR}=$ moderately resistant, presence of small uredia, surrounded by necrotic areas; MR-MS = moderately resistant to moderately susceptible; $\mathrm{MS}=$ moderately susceptible, medium uredia with no necrosis but possibly some distinct chlorosis; MS-S = moderately susceptible to susceptible; and $\mathrm{S}=$ susceptible, presence of large uredia and little or no chlorosis.

${ }^{\mathrm{c}} \mathrm{CIMMYT}=$ International Maize and Wheat Improvement Center, Mexico. 
severity up to interval 2 on individual plants, the term trace (T) was used below 5\% severity. A 5\% interval was used from 5 to $20 \%$ severity and $10 \%$ intervals for higher readings (3). The response of individual plants within each population to the type of stripe rust infection was recorded as follow: $\mathrm{O}=$ no visible infection, with response value $=0$; $\mathrm{Tr}=$ trace severity of resistant type infection, with response value of $0.2 ; \mathrm{R}=$ resistant, necrotic areas with or without minute uredia, with response value of 0.2 ; $\mathrm{R}-\mathrm{MR}=$ resistant to moderately resistant, with response value of $0.3 ; \mathrm{MR}=$ moderately resistant, presence of small uredia, surrounded by necrotic areas, with response value $=0.4$; $\mathrm{MR}-\mathrm{MS}=$ moderately resistant to moderately susceptible, with response value of $0.6 ; \mathrm{MS}=$ moderately susceptible, medium uredia with no necrosis but possibly some distinct chlorosis, with response value of 0.8 ; MS-S = moderately susceptible to susceptible, with response value of 0.9 ; and $S=$ susceptible, presence of large uredia and little or no chlorosis, with response value of 1 .

Severity and reaction were recorded together, with severity first. The coefficient of infection (CI) for the rust was calculated in the manner used in International Maize and Wheat Improvement Center, Mexico (i.e., by multiplying the response value with the intensity of infection in percent). Average CI was derived from the sum of CI values of each entry divided by the number of replications with respect to individual plants (3). The rating scale for disease resistance followed in this study is the same as adapted by the Pakistan Agricultural Research Council, Islamabad for measuring cereal rusts severity (3).

Two readings of disease incidence on the selected plants were recorded with the a lapse of 12 days of the first reading. Using the following formula (2) as a measure of stripe rust resistance, AUDPC was calculated for individual plants from the calculated CI values of the original rust severity data.

$$
\mathrm{AUDPC}=\Sigma\left[\left(X_{\mathrm{i}}+X_{i}+1\right) / 2\right] t_{i}
$$

where $X_{i}$ and $X_{i+1}$ and are severity in the form of CI value on date $i$ and date $i+1$, respectively, and $t_{i}$ is the number of days between date $i$ and date $i+1$.

Selection of parents, development of $B_{1}, B_{2}$, and $F_{2}$ populations, and their evaluation. After performing cluster analysis (not shown) of 45 genotypes for AUDPC (Table 1), four variable genotypes with respect to stripe rust resistance-Bakhtawar-92 (B-92), Frontana, Inqilab-91, and Fakhre Sarhad (FS) were selected as parents for hybridization. Pedigrees, origin, and average AUDPC of the parent genotypes are detailed in Table 1. Using susceptible parents (B-92 and Inqilab-91) as pollen recipients and resistant parents (Frontana and FS) as pollen donors in $F_{1}$, four genotypes were used to attempt two crosses (B-92 $\times$ Frontana and Inqilab-91 $\times$ FS) during November 2004 to April 2005. Six multigenerations $\left(\mathrm{P}_{1}, \mathrm{~F}_{1}, \mathrm{P}_{2}, \mathrm{~B}_{1}\left[\mathrm{~F}_{1} \times\right.\right.$ pollen recipient parent], $B_{2}\left[F_{1} \times\right.$ pollen donor parent $]$, and $F_{2}$ ) of each cross were developed during 2005-06. The generations of the two crosses were planted during 2006-07 in three replications with a RCBD. The row length of $5 \mathrm{~m}$ was kept for each population but number of rows varied (i.e., two rows for parents and $F_{1}$, four rows for each of $B_{1}$ and $B_{2}$, and eight rows for $F_{2}$ populations of all the four crosses in each replication). The plant-to-plant and row-torow spacing was maintained at 10 and $30 \mathrm{~cm}$, respectively. Seed were sown at $2.5 \mathrm{~cm}$ of depth at the rate of two seeds per hill which were later thinned to a single healthy seedling per hill after germination.

For creating artificial epiphytotic conditions, recording disease severity, and working out AUDPC regarding the six populations $\left(\mathrm{P}_{1}, \mathrm{~F}_{1}, \mathrm{P}_{2}, \mathrm{~B}_{1}, \mathrm{~B}_{2}\right.$, and $\left.\mathrm{F}_{2}\right)$, the same methodology was used as was described for the germplasm evaluation. Starting from 24 March 2007, when the wheat plants were at growth stages from booting to milk (30), rust severity was recorded at four intervals with a gap of 1 week between two consecutive readings (i.e., 24 March, 31 March, 7 April, and 14 April 2007). Severity was recorded on the same randomly selected plants (i.e., 60 plants from each of the parental, 90 from the $F_{1}, 150$ from each of the $B_{1}$ and $\mathrm{B}_{2}$, and 210 plants from the $\mathrm{F}_{2}$ populations in all three replications). Data collection was completed within $12 \mathrm{~h}$ on each recording date.

Statistical approach. Gene action and number of major genes for stripe rust resistance was determined by subjecting values of AUDPC to joint segregation analysis (JSA) with five different groups of 24 genetic models $(8-10)$ as described in Table 2 . The observations were recorded on individual plants from each of the six populations: the two homozygous parents $\left(\mathrm{P}_{1}\right.$ and $\left.\mathrm{P}_{2}\right)$, the first filial generation $\left(\mathrm{F}_{1}\right)$, the two backcrosses $\left(\mathrm{B}_{1}\right.$ and $\left.\mathrm{B}_{2}\right)$, and the second filial generation $\left(F_{2}\right)$. Based on assumptions $(8,10)$, the data were subjected to 24 types of genetic models of five groups (Table 2). The most suitable genetic models in each cross were chosen by using maximum log of likelihood values $(6,22,26)$ and Akaike's information criterion (1). As suggested (8,29), further selection of the best-fit model for each cross was made on the basis of least number of significant values of the three statistics: $\mathrm{U}_{1}^{2}=12 \Sigma \mathrm{F}[(\mathrm{Xii})-\mathrm{n} / 2]^{2} / \mathrm{n} \approx \chi^{2}(1)$, to test whether the mean of $\mathrm{Y}_{\mathrm{i}}$ is $1 / 2 ; \mathrm{U}_{2}^{2}=45 / 4 \Sigma \mathrm{F}\left[(\mathrm{Xi})^{2}-\mathrm{n} / 3\right]^{2} / \mathrm{n} \approx \chi^{2}(1)$, to test whether the second momentum of $\mathrm{Y}_{\mathrm{i}}$ is $1 / 3$; and $\mathrm{U}_{2}{ }^{3}=180 \Sigma \mathrm{F}\{[(\mathrm{Xi})-$ $\left.0.5)]^{2}-\mathrm{n} / 12\right\}^{2} / \mathrm{n} \approx \chi^{2}(1)$, to test whether the variance of $Y_{\mathrm{i}}$ is $1 / 12$, where Akaike's information criterion $($ AIC) $=(-2) \log$ (maximum likelihood) +2 (number of independent parameters). A likelihood-ratio test (LRT) was used to choose the simplest type within the model group, where LRT $=\lambda=2 \log \left(\mathrm{L}_{\mathrm{a}}\right)-2 \log \left(\mathrm{L}_{0}\right)$ and $\mathrm{L}_{\mathrm{a}}$ and $\mathrm{L}_{0}$ are the maximum likelihoods under $\mathrm{H}_{\mathrm{a}}$ and $\mathrm{H}_{0}$, respectively. Two other important completely distribution-free tests (Table 3)-Smirnov's statics $\left(\mathrm{nW}^{2}\right)$ and Kolmogorove's statistics $\left(D_{n}\right)$, where $D=\operatorname{Sup}\left|F_{n}(x)-F_{o}(x)\right|$-were used as goodness-of-fit tests to determine whether the selected model sufficiently explains the data. If, for a particular genetic model, none of these five statistics were significant, then it was the indication that the data adequately fit the model. The data were analyzed by using Sin. Exe software, the major gene-polygene mixed inheritance model to a joint analysis of multigenerations (10). In the case of the best-fit model, the values of second-order genetic parameters as well as $\sigma_{m g}{ }^{2}$ and $\sigma_{p g}{ }^{2}$ for $\mathrm{B}_{1}, \mathrm{~B}_{2}$, and $\mathrm{F}_{2}$ were worked out with the help of proposed formulae (10) by using the Excel program of Windows. Under the second-order genetic parameters (Table 4$)$, the phenotypic variation $\left(\sigma_{p}^{2}\right)$ is partitioned into genetic and environmental variation $\left(\sigma_{e}{ }^{2}\right)$ for the two crosses. The genetic component of variation in turn is subdivided into variation due to major genes $\left(\sigma_{m g}{ }^{2}\right)$ and polygene $\left(\sigma_{p g}{ }^{2}\right)$. The values of $\mu_{1}-\mu_{69}$ of Table 5 indicate different means regarding six generations which are to be put in the suggested formulae for calculating first- and second-order genetic parameters (10).

\section{RESULTS}

AUDPC is inversely proportional to the degree of resistance; therefore, genotypes having very low AUDPC are resistant while those with high AUDPC are susceptible (Table 1). Among the resistant genotypes are Frontana, Tatara, FS, and CB 148 while B92, Inqilab-91, Soleman, and Bana-4 are among the highly susceptible lines. On the basis of susceptibility (high AUDPC) and high level of resistance (low AUDPC) to stripe rust, the crosses were performed between highly susceptible and highly resistant genotypes (i.e., B-92 $\times$ Frontana and Inqilab-91 $\times$ FS) in order to determine the number of major genes, influence of polygenes, and their interaction responsible for controlling the disease.

The frequency distribution and the mean values of AUDPC (Table 6) show the tendency of $F_{1}$ and $B_{2}$ toward the $R$ parents (Frontana and FS), which were used as the pollen donor parents in the crosses. The ratio of $\mathrm{R}-\mathrm{MR}$ to $\mathrm{S}$ plants in $\mathrm{F}_{1}, \mathrm{~B}_{1}, \mathrm{~B}_{2}$, and $\mathrm{F}_{2}$ 
for the two crosses further explains the situation (Table 6). Highest phenotypic variances ranged between 2,504.08 (14.19\%) and 6,658.02 (4.14\%) for the segregating progenies (Tables 4 and 6) and indicate that the trait was highly influenced by the environment.

Using the criterion of the maximum log-of-likelihood estimates and smaller AIC values (Table 2), models E, E-1, and B-1 were most suitable for controlling AUDPC in cross 1 whereas models E-1, D-2, and B-1 were suitable for cross 2. On the basis of least number of significant values of the five statistics as goodness-offit tests, models E and E-1 were the best fit for cross 1 and cross 2 , respectively. With the help of formulae, suggested separately for each of the 24 genetic models (10), first- and second-order genetic parameters as presented in Table 4 for corresponding bestfit genetic models (E and E1) for the two crosses were calculated from the component parameters given in Table 5.

As is evident from Table 4, genetic model $\mathrm{E}$ for cross 1 determines mixed additive dominant pistatic effect of major genes plus additive dominant epistasis of polygenes. The additive $\left(d_{a}, d_{b}\right)$ and dominant $\left(h_{a}, h_{b}\right)$ effects contributed by two major genes (A and B) to the control of AUDPC were estimated to be 83.6, 24.8 and $-25.2,-6.4$, respectively. The positive signs of the additive effect with respect to major genes in the cross indicated that AUDPC was controlled by the positive additive action of the major genes. The negative signs of the dominant components of the major genes indicate that resistance to stripe rust was adversely affected by the dominant action of the major genes. The dominant ratios $\left(h_{a} / d_{a}\right.$ and $\left.h_{b} / d_{b}\right)$ of genes A and B were -0.4 and -0.3 , respectively. Therefore, selection for resistant genotypes through a progeny test must be delayed up to advanced generations $\left(\mathrm{F}_{5}\right.$ to $\left.\mathrm{F}_{7}\right)$ when maximum resistant polygenes are accumulated in the individual genotypes. The additive-dominant interaction of gene A over gene B $\left(J_{a b}\right)$ and that of B over A $\left(J_{b a}\right)$ was 14.7 and 24.1 , respectively. The dominant-dominant type of nonallelic interaction $(l)$ was recorded as 10.1 .

In case of cross 2 , the best-fit genetic model was E-1, representing mixed action of two major additive-dominance epistatic genes plus additive-dominant polygenes. The population mean (i.e., $\mathrm{m}=242.9$ ) (Table 4) refers to the average AUDPC, equivalent to the mean of the $\mathrm{F}_{2}$ generation. The negative signs of the dominant effect (-74.3 and -100.6) due to first and second major genes $(\mathrm{A}$ and $\mathrm{B})$ in these crosses show that resistance to stripe rust is controlled by negative dominant effect of the major genes. Additive effect due to the two major genes (A and B) was conspicuous in controlling AUDPC in cross 2 (Inqilab-91 $\times$ FS) with higher effect due to gene A (28.3) than that of gene B (4.3). The negative sign under mixed additive-additive $(i)$ type of genetic effect represents the dispersion of some negative polygenes between the parents (Inqilab-91 and FS) which adversely affect the AUDPC when they combine in the individuals of $\mathrm{F}_{2}$ population. However, the overall additive effect due to polygene was higher and positive (91.3), indicating the pronounced favorable effect of polygene on AUDPC. The highest dominantdominant $(l)$ interaction (101.6) represents the favorability of mixed epistasis due to major genes and polygenes in controlling AUDPC in cross 2 . The dominant effect due to polygenes in the cross was smaller (15.6) but was favorable because of its positive sign value (Table 4).

Because resistance to stripe rust is controlled by two major genes plus polygene, the phenotypic variance $\left(\sigma_{p}^{2}\right)$ in $\mathrm{B}_{1}, \mathrm{~B}_{2}$, and $\mathrm{F}_{2}$ was higher in both of the crosses. The major gene heritability $\left(h_{m g}{ }^{2}\right)$, which is the most important second-order parameter, was higher (i.e., 73.5, 48.9, and 87.1 in $\mathrm{B}_{1}, \mathrm{~B}_{2}$, and $\mathrm{F}_{2}$, respectively) for cross 1 . The polygene heritability $\left(h_{p g}{ }^{2}\right)$, which is the less important component, was smaller and estimated as 16.9, 36.8, and 6.71 for $\mathrm{B}_{1}, \mathrm{~B}_{2}$, and $\mathrm{F}_{2}$, respectively, in cross 1 . Cross 2 also responded in the same way (i.e., higher major gene heritability

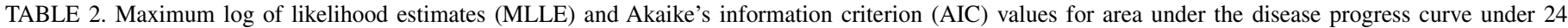
genetic models estimated through the iterated expectation and conditional maximization (IECM) algorithm ${ }^{\mathrm{a}}$

\begin{tabular}{|c|c|c|c|c|}
\hline \multirow[b]{3}{*}{ Model group, code, and implication of model type } & \multicolumn{4}{|c|}{ Cross combination } \\
\hline & \multicolumn{2}{|c|}{ B-92 $\times$ Frontana } & \multicolumn{2}{|c|}{ Inqilab-91 × Fakhre Sarhad } \\
\hline & MLLE & $\mathrm{AIC}$ & MLLE & $\mathrm{AIC}$ \\
\hline \multicolumn{5}{|l|}{ Group 1: One major gene } \\
\hline A-1: additive and dominant & $-3,862.55$ & $7,733.10$ & $-3,900.42$ & $7,808.83$ \\
\hline A-2: additive & $-3,874.50$ & $7,755.00$ & $-3,913.78$ & $7,833.56$ \\
\hline A-3: dominance & $-3,992.06$ & $7,990.12$ & $-4,086.09$ & $8,178.18$ \\
\hline A-4: negative dominance & $-3,922.90$ & $7,851.80$ & $-4,038.12$ & $8,082.24$ \\
\hline \multicolumn{5}{|l|}{ Group 2: Two major genes } \\
\hline B-1: additive dominance and epistasis & $-3,727.13$ & $7,474.26$ & $-3,769.34$ & $7,558.69$ \\
\hline B-2: additive and dominance & $-3,807.06$ & $7,626.12$ & $-3,852.96$ & $7,717.92$ \\
\hline B-3: additive & $-3,858.87$ & $7,725.74$ & $-3,945.91$ & $7,899.82$ \\
\hline B-4: equal additive & $-3,911.65$ & $7,829.32$ & $-3,929.03$ & $7,864.05$ \\
\hline B-5: dominance & $-3,991.57$ & $7,991.15$ & $-4,074.69$ & $8,157.38$ \\
\hline B-6: equal dominance & $-3,991.57$ & $7,989.15$ & $-4,074.69$ & $8,155.38$ \\
\hline \multicolumn{5}{|l|}{ Group 3: Polygene } \\
\hline $\mathrm{C}$ : additive dominance and epistasis & $-3,771.80$ & $7,563.60$ & $-3,788.73$ & $7,597.46$ \\
\hline C-1: additive and dominance & $-3,813.54$ & $7,641.08$ & $-3,828.23$ & $7,670.46$ \\
\hline \multicolumn{5}{|l|}{ Group 4: One major gene + polygene } \\
\hline D: mixed one major gene and additive-dominance-epistasis polygene & $-3,737.84$ & $7,499.68$ & $-3,768.41$ & $7,560.83$ \\
\hline D-1: mixed one major gene and additive-dominance polygene & $-3,759.35$ & $7,536.71$ & $-3,778.32$ & $7,574.65$ \\
\hline D-2: mixed one additive major gene and additive-dominance polygene & $-3,759.35$ & $7,534.71$ & $-3,778.32$ & $7,572.65$ \\
\hline D-3: mixed one dominance major gene and additive-dominance polygene & $-3,807.42$ & $7,630.84$ & $-3,813.94$ & $7,643.88$ \\
\hline D-4: mixed one negative dominance major gene and additive-dominant polygenes & $-3,785.38$ & $7,586.77$ & $-3,793.32$ & $7,602.65$ \\
\hline \multicolumn{5}{|l|}{ Group 5: Two major genes + polygene } \\
\hline E: mixed two major additive-dominance epistatic genes + additive-dominant-epistasis of polygene & $-3,701.76$ & $7,439.53$ & $-3,756.51$ & $7,549.02$ \\
\hline E-1: mixed two major additive-dominance epistatic genes + additive-dominant polygene & $-3,722.78$ & $7,475.57$ & $-3,760.58$ & $7,551.16$ \\
\hline E-2: mixed two major additive-dominant genes + additive-dominant polygene & $-3,765.82$ & $7,553.64$ & $-3,790.63$ & $7,603.26$ \\
\hline E-3: mixed two major additive genes + additive-dominant polygene & $-3,729.67$ & $7,477.34$ & $-3,778.03$ & $7,574.06$ \\
\hline E-4: mixed two major equal additive genes + additive-dominant polygene & $-3,781.47$ & $7,578.94$ & $-3,796.56$ & $7,609.13$ \\
\hline E-5: mixed two major dominant genes + additive-dominant polygene & $-3,800.74$ & $7,619.48$ & $-3,816.85$ & $7,651.71$ \\
\hline E-6: mixed two major equal dominant genes + additive-dominant polygene & $-3,771.56$ & $7,559.12$ & $-3,781.50$ & $7,579.00$ \\
\hline
\end{tabular}

a Source of different model groups and model types $(8,10)$. 
(72.7, 63.1, and 86.3 for $\mathrm{B}_{1}, \mathrm{~B}_{2}$, and $\mathrm{F}_{2}$, respectively) and polygene heritability $\left(22.5,28.1\right.$, and 9.6 for $B_{1}, B_{2}$, and $F_{2}$, respectively).

\section{DISCUSSION}

Using AUDPC for stripe rust as the measure of stripe rust resistance, two wheat crosses (i.e., B-92 $\times$ Frontana and Inqilab$91 \times$ FS) were made where the pollen recipients (B-92 and Inqilab-91, with high AUDPC) were highly susceptible and pollen donors (Frontana and FS, with low AUDPC) were highly resistant genotypes. Number of major genes, presence of polygenes, genetic effects due to individual major genes, and collective effects due polygene controlling stripe rust resistance were determined through JSA (8-10). This statistical approach has the advantage over the method of Kearsey and Pooni (17) because the former has the power to determine the number and effects due to the major genes $\left(d_{a}, d_{b}, h_{a}\right.$, and $\left.h_{b}\right)$ as well as the collective effect of the polygenes " $[\mathrm{d}],[\mathrm{h}]$ " involved in controlling the trait. Moreover, the data were subjected to 24 different genetic models (Table 2) designed for determining gene action in case of six generations (10). According to the procedure, combined effects of the major genes were also determined under the second-order genetic parameters (Table 4). In contrast, the later procedure measures the trait only as the polygenic system without measuring the effect of individual genes (15). The current statistical approach (JSA) and the software specially designed for data analysis of six generations (i.e., $\mathrm{P}_{1}, \mathrm{P}_{2}, \mathrm{~F}_{1} \mathrm{~B}_{1}, \mathrm{~B}_{2}$, and $\mathrm{F}_{2}$ ) has the limitation to determine genetic effects up to two major genes without finding the number of polygenes.

The genotype Frontana was formerly described to have durable resistance to leaf rust (Puccinia recondita $\mathrm{f}$. sp. tritici) at adult plant stage (25) and Inqilab-91 with resistance to stripe rust based on genes $Y r 9$ and $\operatorname{Yr} 27$ (21). Frequency distribution of plant population for AUDPC (Table 6) revealed transgressive segregation with respect to susceptibility and resistance in the $\mathrm{F}_{2}$ segregating generations of the crosses. The tendency of $F_{1}, B_{1}$, and $B_{2}$ toward their respective pollen donor parents in each cross is the indication that resistance to stripe rust is mainly controlled by nuclear genes rather than cytoplasmic factors. Normal distribution of $F_{2}$ and occurrence of transgressive segregates of resistant as well as susceptible types, though very few in the case of each cross (Table 6), indicate the quantitative controlled nature of AUDPC for stripe rust. The transgressive segregation further explains that both the parents in each cross have resistant genes for controlling stripe rust. The susceptible transgressive segregates refer to the fact that some adverse genes were also dispersed in the parents which, on accumulation in $\mathrm{F}_{2}$ individuals, affected the resistance. Susceptible transgressive segregates have also been reported (4) for leaf rust and stripe rust (20) as well as resistant transgressive segregates for Septoria tritici blotch in half diallel crosses for wheat (2) whereas, in the case of some wheat crosses, both susceptible and resistant types of transgressive segregates for stripe rust were reported in $\mathrm{F}_{2}$ and $\mathrm{F}_{3}$ generations (12-14).

TABLE 3. Tests for goodness-of-fit regarding area under the disease progress curve of models B-1, E, and E-1 for cross 1 (Bakhtawar-92 $\times$ Frontana) and cross 2 (Inquilab-91 $\times$ Fakhre Sarhad) ${ }^{\text {a }}$

\begin{tabular}{|c|c|c|c|c|c|c|}
\hline Model & Generation & $\mathrm{U}_{1}^{2}$ & $\mathrm{U}_{2}{ }^{2}$ & $\mathrm{U}_{3}{ }^{2}$ & ${ }_{n} W^{2}$ & $D_{n}$ \\
\hline \multicolumn{7}{|l|}{ Cross 1} \\
\hline \multirow[t]{5}{*}{ E } & $\mathrm{P}_{1}$ & $0.08(0.77)$ & $0.33(0.57)$ & $11.59 * * *$ & $0.28(>0.05)$ & $0.13^{*}$ \\
\hline & $\mathrm{F}_{1}$ & $0.01(0.92)$ & $1.42(0.23)$ & $19.00 * * *$ & $0.43(>0.05)$ & $0.13^{*}$ \\
\hline & $\mathrm{B}_{1}$ & $0.82(0.36)$ & $0.06(0.80)$ & $6.37 * *$ & $0.25(>0.05)$ & $0.07 *$ \\
\hline & $\mathrm{B}_{2}$ & $0.02(0.89)$ & $0.15(0.70)$ & $0.96(0.32)$ & $0.05 *$ & $0.05^{*}$ \\
\hline & $\mathrm{F}_{2}$ & $0.60(0.43)$ & $0.69(0.40)$ & $0.11(0.73)$ & $0.11(>0.05)$ & $0.05^{*}$ \\
\hline \multirow[t]{4}{*}{ B-1 } & $\mathrm{P}_{1}$ & $0.51(0.47)$ & $1.58(0.21)$ & $5.10 * *$ & $0.18 *$ & $0.11 *$ \\
\hline & $\mathrm{B}_{1}$ & $0.00(0.95)$ & $0.03(0.86)$ & $0.24(0.62)$ & $0.04 * *$ & $0.04 * *$ \\
\hline & $\mathrm{B}_{2}$ & $0.01(0.92)$ & $0.00(0.96)$ & $0.03(0.86)$ & $0.04 * * *$ & $0.05^{* * *}$ \\
\hline & $\mathrm{F}_{2}$ & $35.21 * * *$ & $46.81 * * *$ & $19.23(0.15)$ & $3.77(>0.05)$ & $0.21(>0.05)$ \\
\hline \multirow[t]{4}{*}{ E-1 } & $\mathrm{P}_{1}$ & $0.07(0.79)$ & $0.28(0.59)$ & $9.77 * * *$ & $0.24(>0.05)$ & $0.11 * *$ \\
\hline & $\mathrm{F}_{1}$ & $0.00(0.94)$ & $1.18(0.28)$ & $21.15^{* * *}$ & $0.49(>0.05)$ & $0.14^{*}$ \\
\hline & $\mathrm{P}_{2}$ & $0.84(0.36)$ & $2.66(0.10)$ & $8.87 * * *$ & $0.39(>0.05)$ & $0.13 * *$ \\
\hline & $\mathrm{B}_{1}$ & $0.75(0.38)$ & $0.80(0.37)$ & $0.06(0.81)$ & $0.19(>0.05)$ & $0.08 * *$ \\
\hline & $\mathrm{F}_{1}$ & $0.00(1.0)$ & $0.54(0.46)$ & $8.65 * * *$ & $0.19(>0.05)$ & $0.11 * * *$ \\
\hline & $\mathrm{P}_{2}$ & $0.00(1.0)$ & $0.79(0.37)$ & $12.62 * * *$ & $0.24(>0.05)$ & $0.11 * * *$ \\
\hline & $\mathrm{B}_{1}$ & $2.75^{*}$ & $2.16(0.14)$ & $0.30(0.58)$ & $0.34(>0.05)$ & $0.08 * *$ \\
\hline & $\mathrm{B}_{2}$ & $0.01(0.93)$ & $0.00(0.98)$ & $0.20(0.65)$ & $0.03 * *$ & $0.04 * *$ \\
\hline & $F_{2}$ & $1.22(0.27)$ & $2.07(0.15)$ & $2.16(0.14)$ & $0.23(>0.05)$ & $0.07 * *$ \\
\hline \multirow[t]{6}{*}{ E-1 } & $\mathrm{P}_{1}$ & $0.12(0.73)$ & $0.18(0.67)$ & $9.11 * * *$ & $0.24(>0.05)$ & $0.11 * *$ \\
\hline & $\mathrm{F}_{1}$ & $0.00(0.98)$ & $0.52(0.43)$ & $8.71 * * *$ & $0.19(>0.05)$ & $0.11 * *$ \\
\hline & $\mathrm{P}_{2}$ & $0.12(0.73)$ & $1.49(0.22)$ & $12.57 * * *$ & $0.31(>0.05)$ & $0.12 * *$ \\
\hline & $\mathrm{B}_{1}$ & $3.57(0.59)$ & $3.63(0.06)$ & $0.09(0.76)$ & $0.38(>0.05)$ & $0.09 * *$ \\
\hline & $\mathrm{B}_{2}$ & $3.02(0.08)$ & $2.83(0.09)$ & $0.00(0.99)$ & $0.28(>0.05)$ & $0.07 *$ \\
\hline & $\mathrm{F}_{2}$ & $1.20(0.27)$ & $2.77(0.09)$ & $5.83 * *$ & $0.28(>0.05)$ & $0.07 *$ \\
\hline \multirow[t]{3}{*}{ B-1 } & $\mathrm{P}_{1}$ & $0.12(0.73)$ & $0.03(0.84)$ & $0.38(0.54)$ & $0.07 *$ & $0.07 * *$ \\
\hline & $\mathrm{F}_{1}$ & $0.12(0.73)$ & $0.85(0.35)$ & $25.52 * * *$ & $0.60(>0.05)$ & $0.17(>0.05)$ \\
\hline & $\mathrm{P}_{2}$ & $0.14(0.70)$ & $0.00(0.94)$ & $1.28(0.26)$ & $0.09 * *$ & $0.07 * *$ \\
\hline
\end{tabular}

a Probability value shown in parenthesis; *,**, and *** represent significance level at $0.05,0.01$, and 0.001 , respectively. $\mathrm{U}_{1}{ }^{2}, \mathrm{U}_{2}{ }^{2}$, and $\mathrm{U}_{3}{ }^{2}: \chi^{2}$ statistics with 1 degree of freedom; ${ }_{n} W^{2}$ : Smirnov's statistics; $D_{n}$ : Kolmogorov's statistics. The model with least number of significant values relevant to the five statistics is the best fit in each cross. 
TABLE 4. Estimates of first- and second-order genetic parameters for stripe rust resistance (area under the disease progress curve) in two bread wheat crosses $^{\mathrm{a}}$

\begin{tabular}{lllcc}
\hline & \multicolumn{4}{c}{ Estimates } \\
\cline { 2 - 5 } Parameters & First order & $\mathrm{B}_{1}$ & $\mathrm{~B}_{2}$ & $\mathrm{~F}_{2}$ \\
\cline { 3 - 5 } & & & \multicolumn{3}{c}{ Second order } \\
\hline
\end{tabular}

Cross 1

First order

$m_{1}=\quad 125.6$

$m_{2}=\quad 166.2$

$m_{3}=\quad 175.3$

$m_{4}=\quad 141.5$

$m_{5}=\quad 165.2$

$m_{6}=\quad 145.9$

$d_{a}=\quad 83.6$

$d_{b}=\quad 24.8$

$h_{a}=\quad-25.5$

$h_{b}=$

$h_{a} / d_{a}=$

$h_{b} / d_{b}=$

$i=$

$j_{a b}=$

$j_{b a}=$

$l=$

Second order

$\sigma_{p}{ }^{2}=$

$\sigma_{m g}^{2}=$

$\sigma_{e}^{2}=$

$\sigma_{p g}{ }^{2}=$

$h_{m g}(\%)$

$h_{p g}{ }^{2}(\%)$

Cross 2

First order

$m=$

$d_{a}=$

$d_{b}=$

$h_{a}=$

$h_{b}=$

$h_{a} / d_{a}=$

$h_{b} / d_{b}=$

$i=$

$j_{a b}=$

$j_{b a}=$

$l=$

[d] $=$

$[\mathrm{h}]=$

Second order

$\sigma_{p}{ }^{2}=$

$\sigma_{m g}^{2}=$

$\sigma_{e}^{2}=$

$\sigma_{p g}{ }^{2}=$

$h_{m g}(\%)$

$h_{p g}{ }^{2}(\%)$

-25.5
-6.4

$-0.4$

$-0.3$

$-0.8$

14.7

24.1

10.1

$\ldots$

$\ldots$

$\cdots$

$\ldots$

$\ldots$

$\ldots$

242.9

28.3

4.3

$-74.3$

$-100.6$

$-2.6$

$-23.2$

$-49.1$

$-83.2$

$-109.8$

101.6

91.3

15.6

(1)

$\ldots$
$\ldots$

$\cdots$

$\cdots$
$\cdots$

$\ldots$

$\ldots$

$\mathrm{B}_{1}+\mathrm{B}_{2}-\mathrm{F}_{2}$

TABLE 5. Maximum likelihood estimates of component parameters regarding area under the disease progress curve for two wheat crosses in their respective best-fit models ${ }^{\mathrm{a}}$

\begin{tabular}{lcc}
\hline & \multicolumn{2}{c}{ Estimate } \\
\cline { 2 - 3 } Parameter & Cross 1 & Cross 2 \\
\hline$\mu_{1}$ & 233.3 & 309.53 \\
$\mu_{2}$ & 155.0 & 185.32 \\
$\mu_{3}$ & 65.9 & 78.23 \\
$\mu_{41}$ & 249.1 & 287.82 \\
$\mu_{42}$ & 233.4 & 124.8 \\
$\mu_{43}$ & 175.4 & 124.54 \\
$\mu_{44}$ & 130.2 & 207.04 \\
$\mu_{51}$ & 154.0 & 148.04 \\
$\mu_{52}$ & 101.3 & 228.41 \\
$\mu_{53}$ & 60.5 & 175.61 \\
$\mu_{54}$ & 55.9 & 115.52 \\
$\mu_{61}$ & 256.6 & 258.32 \\
$\mu_{62}$ & 240.9 & 95.29 \\
$\mu_{63}$ & 208.7 & 299.87 \\
$\mu_{64}$ & 182.9 & 95.04 \\
$\mu_{65}$ & 137.7 & 177.54 \\
$\mu_{66}$ & 85.1 & 257.91 \\
$\mu_{67}$ & 91.0 & 299.87 \\
$\mu_{68}$ & 44.3 & 205.1 \\
$\mu_{69}$ & 39.7 & 145.0 \\
$\sigma^{2}$ & 355.6 & 276.1 \\
$\sigma_{4}{ }^{2}$ & 931.7 & $1,083.2$ \\
$\sigma_{5}^{2}$ & 759.4 & $1,560.6$ \\
$\sigma_{6}{ }^{2}$ & 355.6 & 963.4 \\
\hline
\end{tabular}

${ }^{a}$ Cross $1=$ Bakhtawar-92 $\times$ Frontana (model E) and cross $2=$ Inqilab-91 $\times$ Fakhre Sarhad (model E-1). $\sigma^{2}$ : Phenotypic variance of $\mathrm{P}_{1}, \mathrm{~F}_{1}$, and $\mathrm{P}_{2} ; \sigma_{4}^{2}$ : polygenic + environmental variance of $\mathrm{B}_{1} ; \sigma_{5}{ }^{2}$ : polygenic + environmental variance of $\mathrm{B}_{2} ; \sigma_{6}{ }^{2}$ : polygenic + environmental variance of $\mathrm{F}_{2}$.

two crosses have values with negative sign, referring to the recessively controlled nature of AUDPC in both the crosses. The positive sign and higher values of the additive effects due to the major genes show predominance of the additive effect on AUDPC in both the crosses. The negative signs of the dominant ratios $\left(h_{a} / d_{a}\right.$ and $h_{b} / d_{b}$ ) of the gene A and B in both the crosses further indicate the predominance of the additive gene action due to major genes rather than the dominant effect. The negative signs of nonallelic dominant interaction of the two major genes as well as of additive-additive effect $(i)$ in the cross indicate the dispersion of some adverse genes in parents (B-92 and Frontana) which negatively affected resistance to stripe rust. The estimated additive effects due to major gene $\mathrm{A}$ and $\mathrm{B}$ in the crosses were 28.3 to 83.6 and 4.3 to 24.8 , respectively (Table 4 ). The negative and positive signs of the additive as well as dominant effect due to the major genes and polygenes in different crosses may occur due to the difference in the genetic background of the parents involved in the crosses (15). Generally, the dominant and additive effects exerted by polygenes were less than those of the major genes, because the polygenes contributed a very low fraction to the phenotypic variation $\left(\sigma_{p}^{2}\right)$ with very low values of polygene heritability $(16.9,36.8$, and $6.7 \%$ in cross 1 and 22.5, 28.1, and $9.6 \%$ in cross 2 for $\mathrm{B}_{1}, \mathrm{~B}_{2}$, and $\mathrm{F}_{2}$, respectively).

The present results are in accordance with those of Jiankang and Gai (15) regarding resistance to beanfly in soybean with respect to heritability values due to major genes as well as polygenes. Under the mix epistasis effect of both major and polygenes for cross 1, negative genes for controlling AUDPC were present among the two parents. This suggests that progeny selection of resistant genotypes should be delayed to advanced generations, until maximum resistant polygenes are accumulated in more or less homozygous condition in the individual plants. An additive effect with respect to stripe rust resistance has also been reported in wheat crosses (16). The additive-dominant effect $(J)$ due to the second major gene and dominant-dominant effect $(l)$ under epistasis was positive for cross 1 . These effects have previously been 
TABLE 6. Frequency distribution of plant population under level of area under the disease progress curve (AUDPC) and ratios of resistant (R), moderately resistant (MR), and susceptible (S) plants in $\mathrm{P}_{1}, \mathrm{~F}_{1}, \mathrm{~B}_{1}, \mathrm{~B}_{2}$, and $\mathrm{F}_{2}$ generations (Gen.) of two bread wheat (Triticum aestivum $\mathrm{L}_{\text {.) }}$ crosses ${ }^{\mathrm{a}}$

\begin{tabular}{|c|c|c|c|c|c|c|c|c|c|c|c|c|c|c|c|c|c|c|c|}
\hline \multirow[b]{2}{*}{ Gen. ${ }^{b}$} & \multicolumn{14}{|c|}{ Range of AUDPC } & \multirow[b]{2}{*}{$\mathrm{Size}^{\mathrm{c}}$} & \multirow[b]{2}{*}{$\mathrm{R}: \mathrm{MR}: \mathrm{S}^{\mathrm{d}}$} & \multirow[b]{2}{*}{$\mathrm{AUDPC}^{\mathrm{e}}$} & \multirow[b]{2}{*}{ Variance $^{f}$} & \multirow[b]{2}{*}{$\mathrm{SD}( \pm)^{\mathrm{g}}$} \\
\hline & 0 & $25-$ & 50 & $75-$ & $100-$ & 125 & 150 & $175-$ & 200 & $225-$ & 250 & $275-$ & $300-$ & $325-$ & & & & & \\
\hline \multicolumn{20}{|c|}{ Cross 1} \\
\hline $\mathrm{P}_{1}$ & $\ldots$ & $\cdots$ & $\cdots$ & $\cdots$ & $\ldots$ & $\ldots$ & $\ldots$ & 3 & 20 & 19 & 14 & 4 & $\ldots$ & $\ldots$ & 60 & $0: 0: 60$ & 233.28 & 545.16 & 23.35 \\
\hline $\mathrm{P}_{2}$ & $\ldots$ & 8 & 20 & 20 & 11 & 1 & $\ldots$ & $\ldots$ & $\ldots$ & $\ldots$ & $\ldots$ & $\ldots$ & $\ldots$ & $\ldots$ & 60 & 60:0:0 & 65.98 & 565.72 & 23.78 \\
\hline $\mathrm{B}_{1}$ & $\ldots$ & $\ldots$ & & 5 & 29 & 25 & 24 & 21 & 19 & 13 & 7 & 7 & $\ldots$ & $\ldots$ & 150 & $10: 53: 87$ & 192.60 & $3,699.50$ & 60.82 \\
\hline $\mathrm{B}_{2}$ & 11 & 27 & 29 & 24 & 18 & 14 & 9 & 8 & 6 & 4 & & & . & . & 150 & $87: 51: 12$ & 93.75 & $2,504.08$ & 50.04 \\
\hline $\mathrm{P}_{1}$ & $\ldots$ & $\ldots$ & $\ldots$ & $\ldots$ & $\ldots$ & $\ldots$ & $\ldots$ & $\ldots$ & 10 & 12 & 16 & 13 & 9 & $\ldots$ & 60 & $0: 0$ & 308.65 & 349.27 & 15.22 \\
\hline $\mathrm{F}_{1}$ & $\ldots$ & $\ldots$ & $\ldots$ & $\ldots$ & $\ldots$ & 14 & 18 & 26 & 17 & 15 & $\ldots$ & $\ldots$ & $\ldots$ & $\ldots$ & 90 & $0: 22: 68$ & 185.34 & 138.21 & 11.76 \\
\hline $\mathrm{P}_{2}$ & $\ldots$ & $\ldots$ & 5 & 22 & 22 & 7 & 4 & . & & & & 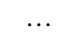 & $\ldots$ & $\ldots$ & 60 & 60:0:0 & 79.14 & 403.36 & 20.08 \\
\hline $\mathrm{B}_{1}$ & $\ldots$ & $\ldots$ & 5 & 8 & 23 & 15 & 15 & 14 & 15 & 15 & 12 & 12 & 7 & 9 & 150 & $11: 54: 85$ & 198.04 & $5,833.14$ & 76.30 \\
\hline $\mathrm{B}_{2}$ & $\ldots$ & 10 & 8 & 12 & 21 & 23 & 24 & 23 & 18 & 11 & $\ldots$ & $\ldots$ & $\ldots$ & $\ldots$ & 150 & $26: 67: 57$ & 157.77 & $3,138.64$ & 56.02 \\
\hline $\mathrm{F}_{2}$ & $\ldots$ & 6 & 12 & 15 & 20 & 18 & 19 & 19 & 18 & 19 & 21 & 21 & 14 & 8 & 210 & $33: 57: 120$ & 194.46 & $6,658.02$ & 81.60 \\
\hline
\end{tabular}

a According to rating scale, $0-2=\mathrm{R}, 3-6=\mathrm{MR}$, and $7-9=\mathrm{S}$ reactions (12).

${ }^{\text {b }}$ Cross $1=$ Bakhtawar-92 $\left(\mathrm{P}_{1}\right) \times$ Frontana $\left(\mathrm{P}_{2}\right)$ and cross $2=\operatorname{Inqilab}-91\left(\mathrm{P}_{1}\right) \times$ Fakhre Sarhad $\left(\mathrm{P}_{2}\right)$.

c Sample size.

${ }^{\mathrm{d}}$ Ratio of R:MR:S.

e Mean AUDPC.

${ }^{\mathrm{f}}$ Phenotypic variance.

g Standard deviation.

reported for leaf rust in some wheat crosses (4). An additive or modifying action of two genes for stripe rust in a segregating generation was reported to result from a cross between $\mathrm{S}$ and $\mathrm{R}$ cultivars of wheat (12). Segregation ratio of 1:2:5 for R, MR, and $S$ has been reported in $F_{2}$ and $F_{3}$, suggesting the involvement of three genes with epistasis for resistance to stripe rust at seedling stage in wheat (13). Two genes have been suggested with additive effect to be responsible for stripe rust resistance in a wheat cross between highly R and S parents (20). Based on joint scaling test, gene action regarding durable, high-temperature adult-plant resistance for stripe rust was studied in parental, $F_{1}, F_{2}$, and backcross populations for some crosses in wheat, the AUDPC being under the control of epistasis with a significant additiveadditive component (28).

Using generation mean analysis, an additive-dominance model (absence of epistasis) digenic epistasis with predominant additive effect, significant additive-additive ' $i$ ', and dominant-dominant ' $l$ ' types of epistatic interaction for powdery mildew were reported in wheat crosses (5). The previous findings are more or less in correspondence with those of the present study. However, the contradictions between the present and previous results may be due to the fact that either diallel or generation mean analysis were used in the previous studies as the statistical approach, which measure the genetic effect as the polygenic system. These approaches have no power to determine the effect of the individual major genes and aggregate effect of the polygene. Moreover, the difference in the genetic background of the material and different environmental conditions used in the present and past experimentations may further lead to the deviation in the results.

In summary, $F_{2}$ of the two crosses was normally distributed along the level of AUDPC for stripe rust, with transgressive segregates on both lower and upper limits. This situation indicates the dispersion of both resistant and adverse genes in the parents, respectively, for stripe rust. The tendency of $\mathrm{B}_{1}$ and $\mathrm{B}_{2}$ toward their respective pollen donor parents implies that resistance to stripe rust is under the control of nuclear genes rather than cytoplasmic factors. AUDPC for stripe rust in both the crosses was observed to be controlled by two major genes and some polygenes with pronounced additive interaction. In cross 1, additive gene interaction was due to the major genes whereas, in cross 2 , it was due to polygenes to control the resistance. Selection for resistant recombinants must be delayed to the advanced generations due to the additively controlled nature of the disease.
Highest environmental variation $\left(\sigma_{p}^{2}\right)$ was found in $\mathrm{B}_{1}, \mathrm{~B}_{2}$, and $\mathrm{F}_{2}$ generations of the crosses. The major gene variation $\left(\sigma_{m g}{ }^{2}\right)$ and heritability $\left(h_{m g}{ }^{2}\right)$ were higher compared with those of the polygene (i.e., $\sigma_{p g}{ }^{2}$ and $h_{m g}{ }^{2}$, respectively).

\section{ACKNOWLEDGMENTS}

M. Irfaq acknowledges the award of a scholarship by the Higher Education Commission of Pakistan (HEC) as a visiting scientist to Institute of Biotechnology, Jiangsu Academy of Agricultural Sciences (JAAS), Nanjing, China where the statistical approach was applied. We thank Farooq-e-Azam, Director of the NIFA; Ma Hongxiang, Director of the Institute of Biotechnology, JAAS; and two anonymous reviewers for critically reviewing and correcting the manuscript.

\section{LITERATURE CITED}

1. Akaike, H. 1977. On the entropy maximum principle. Pages 27-41 in: Applications of Statistics. P. R. Krishnaiah, ed. North-Holland Publishing Company, Amsterdam.

2. Arama, P. F., Parlevliet J. E., and Van Silfhout C. H. 2000. Trangressive segregation for resistance in wheat to Septoria tritici blotch. Afr. Crop Sci. J. 8:213-222.

3. Aslam, M. 1982. Uniform procedure for development and release of improved wheat varieties. Mimeograph, PARC, Islamabad. Page 32 in: Report on Screening of Wheats Against Yellow Rust and Leaf Rust under NWDSN and NUWYT during 2006-2006. Crop Diseases Research Programme, Institute of Plant and Environmental Protection, National Agriculture Research Centre, Pakistan.

4. Bjarko, M. E., and Line, R. F. 1988. Heritability and number of genes controlling leaf rust resistance in four cultivars of wheat. Phytopathology 78:458-461.

5. Das, M. K., Rajaram S., Mundt C. C., and Kronstad, W. E. 2004. Number of genes controlling slow rusting resistance to leaf rust in five spring wheat cultivars. Ann. Appl. Biol. 145:91-94.

6. Dempster, A. P., Laird, N. M., and Robin, D. B. 1977. Maximum likelihood from incomplete data via the EM algorithm. J. R. Stat. Soc. 39:1-38.

7. Doling, D. A. 1965. A method for the transformation of field data for comparing the mildew resistance of cereal varieties and the systemic deviation of the values in NIAB farmer's leaflets. J. Natl. Inst. Agric. Bot. 10:169-179.

8. Gai, J. Y., and Wang, J. K. 1998. Genetic system of quantitative traits in plants. Theor. Appl. Genet. 7:162-1168.

9. Gai, J. Y., Yongjun, W., Xiaolei, W., and Shouyi, C. 2007. A comparative study on segregation analysis and QTL mapping of quantitative traits in plants-with a case in soybean. Front. Agric. China 1:1-7.

10. Gai, J. Y., Zhang, Y., and Jiankang, W. 2003. Mixed genetic model for two 
major genes plus multi-genes. Pages 277-285 in: Genetic System of Quantitative Traits in Plants, 1st ed. Science Press, Beijing.

11. Hojjatollah, G. 2005. Variability of Puccinia striiformis in Iran. Page 64 in: Proc. Second Asian Conf. Plant Pathol. Facult. Sci. Natl. Univ. Singapore.

12. Imtiaz, M., Cromey, M. G., Hampton, J. G., and Ahmad, M. 2003. Inheritance of durable adult plant resistance to stripe rust (Puccinia striiformis f. sp. tritici) in 'Otane' wheat (Triticum aestivum). N. Z. J. Crop Hortic. Sci. 31:23-31.

13. Imtiaz, M., Cromey, M. G., Hampton, J. G., and Hill, M. J. 2003. Inheritance of seedling resistance to stripe rust (Puccinia striifomis $\mathrm{f}$. $\mathrm{sp}$. tritici) in 'Otan' and 'Tritea' wheat (Triticum aestivum). N. Z. J. Crop Hortic. Sci. 31:15-22.

14. Imtiaz, M., Cromey, M. G., Hampton, J. G., and Ogbonnaya, F. C. 2005. Genetics of stripe rust resistance in 'Karamu' wheat. Aust. J. Agric. Res. 56:619-624.

15. Jiankang, W., and Gai, J. 2001. Mixed inheritance model for resistance to agromyzid beanfly (Melanagromyza sojae Zehntner) in soybean. Euphytica 122:9-18.

16. Jing, F., Zhang, Z., Li, G., Zhou1, Y., Wang, H., Guo, Q., and Sun, J. 2007. Inheritance of resistance to stripe rust in winter wheat cultivars Aquileja and Xian Nong 4. J. Appl. Genet. 48:43-46.

17. Kearsey, M. J., and Pooni H. S. 1996. The Genetic Analysis of Quantitative Traits. Champan and Hall, London.

18. Line, R. F., Konzak, C. F., and Alan, R. E. 1974. Evaluating resistance to Puccinia striiformis in wheat. Induced mutation for disease resistance in crop plants. Pages 125-132 in: Proc. Res. Co-ordination Meet. IAEA, Austria.

19. Loegering, W. Q. 1959. Methods for recording cereal rust data U.S.D.A. international spring wheat nursery. Page 32 in: Report on Screening of Wheats Against Yellow Rust and Leaf Rust Under NWDSN and NUWYT During 2006-2006. Crop Diseases Research Programme, Institute of Plant and Environmental Protection, National Agriculture Research Centre, Islamabad, Pakistan.

20. Ma, H., Singh, R. P., and Abdalla, O. 1997. Resistance to stripe rust in five durum wheat cultivars. Plant Dis. 81:27-30.

21. McDonald, D. B., McIntosh, R. A., Wellings, C. R., Singh, R. P., and Nelson, J. C. 2004. Cytogenetical studies in wheat XIX. Location and linkage studies on gene $Y r 27$ for resistance to stripe (yellow) rust. Euphytica 136:239-248.

22. McLachlan, G. J. 1988. Mixture models: inference and applications to clustering. Marcel Dekker, Inc., New York. Pages 10-18 in: Jiankang, W., and Gai, J. 2001. Mixed inheritance model for resistance to agromyzid beanfly (Melanagromyza sojae Zehntner) in soybean. Euphytica 122:918

23. Peterson, R. F., Campbell, A. B., and Hannah, A. E. 1948. A diagnostic scale for estimating rust intensity on leaves and stems of cereals. Can. J. Res. 26:496-500.

24. Rattu, A. R., Akhtar, M. A., Fayyaz, M., and Bashir, M. 2007. Pages 1314 in: Report on Screening of Wheats Against Yellow Rusts and Leaf Rusts Under NUWYT and NWDSN During 2005-2006. Crop Diseases Research Programme, Institute of Plant and Environmental Protection, National Agriculture Research Centre (NARC), Islamabad, Pakistan.

25. Singh, R. P., and Rajaram, S. 1992. Genetics of adult-plant resistance to leaf rust in 'Frontana' and three CIMMYT wheats. Genome 35:24-31.

26. Wang J. K., and Gai J. Y. 1997. Identification of major gene and polygene mixed inheritance and estimation of genetic parameters in $\mathrm{F}_{2}$ progeny. Chin. J. Genet. 24:181-190.

27. Wang, X., Zheng, W., Buchenauer, H., Zhao, J., Han, Q., Huang, L., and Kang, Z. 2008. The development of a PCR-based method for detecting Puccinia striiformis latent infections in wheat leaves. Eur. J. Plant Pathol. 120:241-247.

28. Xianming, C., and Line, R. F. 1995. Gene action in wheat cultivars for durable, high-temperature, adult-plant resistance and interaction with race-specific, seedling resistance to Puccinia striiformis. Phytopathology 85:567-572.

29. Yuan-Ming, Z., Gai, J. Y., and Yang, Y. H. 2003. The EIM algorithm in the joint segregation analysis of quantitative traits. Genet. Res. 81:157-163

30. Zadoks, J. C., Chang, T. T., and Konzak, C. F. 1974. A decimal code for the growth stages of cereals. Weed Res. 14:415-421. 